\title{
Visual symptoms of trunk diseases do not predict vine death
}

\author{
D.C. Mundy ${ }^{1}$ and A.R.G. McLachlan ${ }^{2}$ \\ ${ }^{1}$ The New Zealand Institute for Plant \& Food Research Limited, \\ Marlborough Wine Research Centre, P.O. Box 845, Blenheim, New Zealand \\ ${ }^{2}$ The New Zealand Institute for Plant \& Food Research Limited, Private Bag 11600, \\ Palmerston North, New Zealand \\ Corresponding author: dion.mundy@plantandfood.co.nz
}

\begin{abstract}
Grapevine trunk diseases are the main reason for vine death in older vineyards. These deaths result in economic losses and reduce the productive life of the vineyard. On six occasions during a 10-year period, a single vineyard in Marlborough was monitored for vine deaths. A visual assessment of trunk disease symptoms (low canopy vigour and cankers) in individual vines showed that these symptoms did not predict vine death at the next assessment. The method of visual assessment is discussed in the context of other Sauvignon blanc vineyards in Marlborough that were similarly assessed, but over a shorter time period (within a year). To predict vineyard longevity for the New Zealand industry, improved visual assessments or an alternative method of monitoring vine health status is required.
\end{abstract}

Keywords grapevine trunk disease, eutypa dieback, botryosphaeria dieback

\section{INTRODUCTION}

Grapevine trunk diseases cause crop losses and vine deaths worldwide, resulting in direct and indirect costs to the producers. In California, Eutypa lata (causal agent of eutypa dieback) was estimated to cost grape producers over US $\$ 260$ million in 1999 (Gubler et al. 2005). In Australia, E. lata was calculated to reduce production by $860 \mathrm{~kg} / \mathrm{ha}$ when foliar symptoms were detected in $30 \%$ of Shiraz vines, resulting in direct losses of over AU $\$ 1,000 /$ ha (Wicks \& Davies 1999). The Australian example did not include indirect costs associated with uneven berry maturity, vine reworking (training of new trunks) or replacement needed because of eutypa dieback. Direct losses can be expected from the time that foliar symptoms develop, as the vines lose vigour and die back. Predicting vine death from trunk diseases as early as possible could improve productivity by providing the information growers need to determine whether to treat infected vines or to remove them from the vineyard. Currently, the only tool that wine companies have for predicting possible vine deaths is visual assessment of trunk disease symptoms (Sosnowski et al. 2012).

In forestry systems, infection by wood-invading fungi and symptom expression have been shown to occur under different weather conditions separated by time, leading to the hypothesis that weather requirements for symptom expression in grapevine trunk diseases may be different from those for infection and colonisation (Mundy \& Manning 2011). If seasonal weather conditions do not favour 
symptom expression, a visual assessment might underestimate vine colonisation and the risk of vine death. When modelling the possible economic impact of trunk diseases researchers have used scenarios of different effectiveness of controls to calculate benefits (Baumgartner et al. 2014). Rates of vine death due to no active management during a scenario can change the economic return. To be able to make an economic case for preventive management practices or vineyard removal, robust information on rates of vine deaths is required.

The area of grapes in the Marlborough region has increased rapidly in recent years. In 1999, Marlborough had less than 3,500 ha of producing vineyards (Anon. 2000). In 2014 that area had expanded to 23,000 ha of producing vines (New Zealand Winegrowers 2014). Foliar symptoms and vine deaths are not commonly observed in vines younger than 12 years old. As Marlborough is a relatively new grape-growing region, long-term data sets for vine deaths have not been collected. In longer established grape-growing regions such as California, growers and advisers can provide historical information which can be used for modelling (Baumgartner et al. 2014).

Visual symptoms of trunk diseases (vines with growth from only half the head, cankers, low vigour and stunted shoots) can occur before vine deaths are observed, so a visual assessment method may provide an indication of the potential vine deaths due to trunk disease. Visual assessments have indicated the presence of trunk disease before widespread reporting of trunk disease in wine regions (Sosnowski et al. 2012). At the time of publication, some visual assessments of vines have been conducted by the wine industry but no attempts to relate visual assessment to vine death have been reported in New Zealand.

In addition to eutypa dieback, botryosphaeria dieback caused by Botryosphaeria spp., has also been recorded in symptomatic vineyards across New Zealand wine-producing regions (Mundy et al. 2009). Both diseases can result in poor canopy growth and vine mortality and are managed in New Zealand by application of wound dressings to prevent infection (Mundy \& Manning 2010). Eutypa dieback has the distinctive symptom of stunted, chlorotic shoots in late spring as a result of toxin production (Sosnowski et al. 2007). However, this symptom is not consistently expressed in all infected vines in every season (Mundy \& Manning 2011). Vines with mixed infections of both diseases were commonly detected during surveys when isolations were made from symptomatic vines (Mundy et al. 2009). Because vineyard management practices in New Zealand are the same for both diseases, precise diagnosis is not always carried out or necessary, as both can result in vine death, and thus the treatment is the same.

In 2007, two Marlborough vineyards were sampled for fruit quality on vines with and without trunk disease symptoms. The Sauvignon blanc vines sampled at one of these vineyards had significantly lower soluble solids contents and nitrogen concentrations in juice from the symptomatic vines than from the paired control vines (Mundy \& Cocchi 2007). Given the potential severity of the trunk disease in this Sauvignon blanc vineyard, it was monitored for visual symptoms of trunk diseases and vine deaths over ten years. The aim was to determine whether it would be possible to estimate the rate of vine deaths based on visual symptoms of trunk disease.

\section{METHODS AND MATERIALS}

The selected Marlborough vineyard was planted with Sauvignon blanc (mass selected clone) in 1989 on SO4 rootstock with a 4-cane vertical shoot positioning trellis, referred to as Block 26. Vines were planted on $3 \mathrm{~m}$ row spacing, in bays of four vines, with 1850 vines per ha. Visual surveys of vines were conducted on six occasions: January 2006, February 2008, January 2009, January 2013, December 2014 and January 2016. On each sampling date the same 16 rows were assessed. The eight longest rows (numbered 169 to 176 , with 66 bays and 264 vines per row) and eight rows in the centre of the block (numbered 69 to 76 , with $52-53$ bays and 207-211 vines per row) were selected for surveying. Vines were scored on each occasion for the presence or absence of visual symptoms which included low vigour, 
cankers, and dead vines; gaps where vines had been removed were also recorded. The cause of individual vine death was not ascertained. When vines had been replanted into a gap, that space was still recorded as a gap, as young replacement vines do not provide visual symptoms.

Presence or absence of visual symptoms in 2013 for 27 vineyard blocks in the region with the same rootstock, including Block 26, was obtained from a commercial wine company.

The numbers of vines in each category (dead or gap, diseased as assessed visually (vines with growth from only half the head, cankers, low vigour and stunted shoots) or healthy) in each bay were recorded for each sample date ( $n=3784$ vines on each occasion).

Following fruit composition measurements in March 2007 of 22 visually assessed individual vines (Mundy \& Cocchi 2007), 11 paired and adjacent vines (diseased and healthy) were sampled for presence of fungi. Samples were collected by coring the trunks with a MATTSON N 4333 forestry corer which removed a $5-\mathrm{mm}$ core ca $80 \mathrm{~cm}$ up the trunk, passing directly through the wood until the bark was ruptured on the far side. The corer was cleaned between samples with $70 \%$ ethanol to prevent cross-contamination. The entire core sample was transferred in a sterile tube to the laboratory. Each core was surface sterilised for $30 \mathrm{~s}$ in $70 \%$ ethanol, $2 \mathrm{~min}$ in $3.5 \% \mathrm{w} / \mathrm{v}$ sodium hypochlorite and $30 \mathrm{~s}$ in $70 \%$ ethanol. Samples were cut into 5- to 10-mm pieces and five pieces placed on potato dextrose agar (PDA; DIFCO) amended with $100 \mu \mathrm{g} / \mathrm{ml}$ streptomycin sulphate and $100 \mu \mathrm{g} / \mathrm{ml}$ penicillin $\mathrm{G}$ potassium salts. There were two plates per vine. These were incubated at $20^{\circ} \mathrm{C}(12: 12 \mathrm{~h}$ light:dark). After 1 week, fungi were identified according to their morphological features. Slower growing fungi were sub-cultured from the plates into pure culture for later identification. Additional wood samples were taken and processed as above, from vines that had been destructively
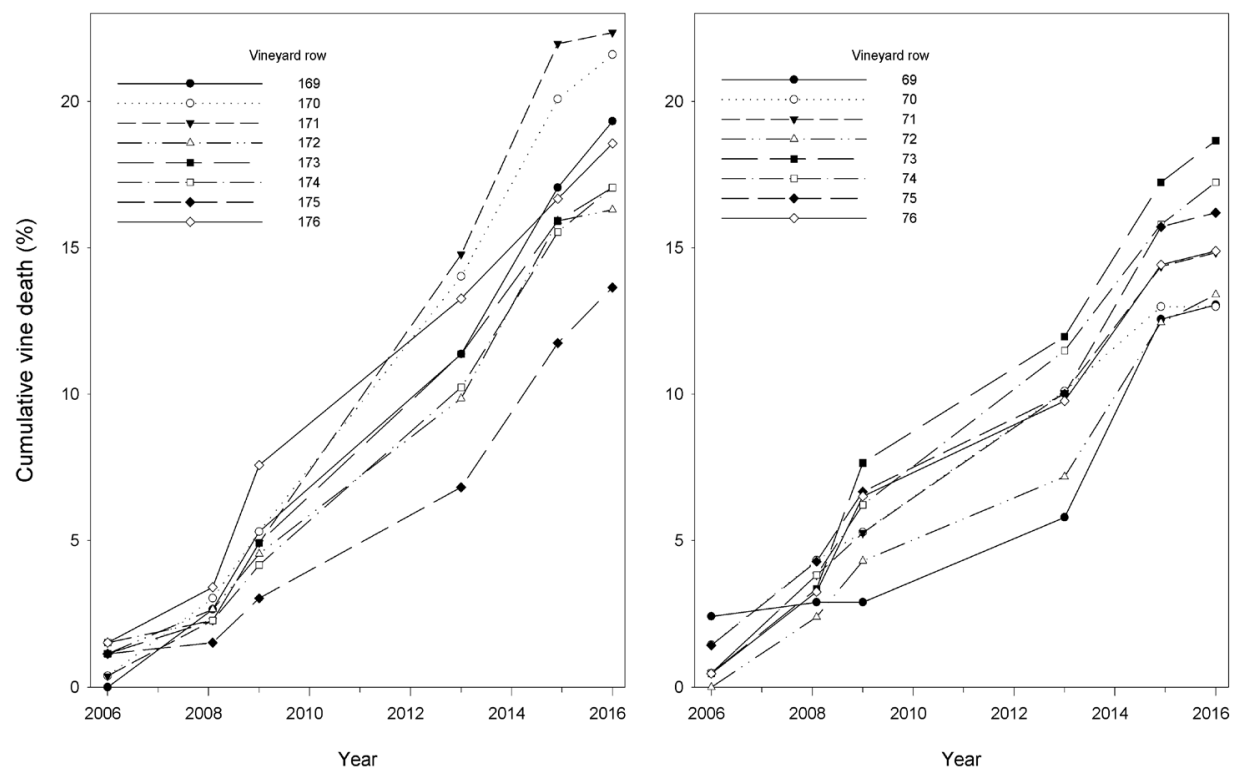

Figure 1 Cumulative Marlborough Sauvignon blanc grapevine deaths in 16 vineyard rows over ten years monitored in Block 26 (Table 4). Rows 169-176 (left) were the longest rows, with 264 plants/row; rows 69-76 (right) were in the centre of the block, with 207-211 plants/row. 
sampled during demonstration field days.

\section{RESULTS}

Cumulative vine death per row was plotted to determine if future vine death could be predicted from past observed rates of vine deaths, without reference to visual symptoms (Figure 1 ). In the initial survey in January 2006, 5.9\% $(n=223)$ of the vines surveyed ( $n=3784$ vines) had visual symptoms, with $0.9 \%(n=34)$ gaps/dead vines (Table 1). In subsequent surveys some of the vines that were originally recorded as having visual symptoms no longer exhibited any symptoms. For example, of the 41 vines that were newly recorded as dead/gap in the January 2016 survey, 12 (29.3\%) had changed from showing foliar symptoms to being healthy in previous surveys (Table 2).

When the numbers of vines were expressed as percentages of the initial January 2006 numbers (with vine deaths cumulative), about $14 \%$ of the vines that initially showed visual symptoms were dead two years later and $66 \%$ had visible symptoms (Table 3 ). This contrasts with those vines initially recorded as healthy, of which only $1.3 \%$ were dead two years later and $16.6 \%$ had visible symptoms. After ten years, the initially healthy vines had the same cumulative percentage dead (14\%) as the initially symptomatic vines did after only two years.

Organisms isolated in 2007 included grapevine trunk pathogens in both the visually assessed vines and in the healthy controls (Table 4). None of the eleven vines without symptoms in 2007 died before December 2015.

During the period of observations, vines outside survey rows but within the same vineyard block that were destructively sampled showed the characteristic wedge-shaped staining associated with both trunk disease pathogens. When plated using the method described above for core samples, wood samples from the stained vines always confirmed the presence of Botryosphaeria spp., Eutypa lata, or both.

Trunk disease visually assessed by a

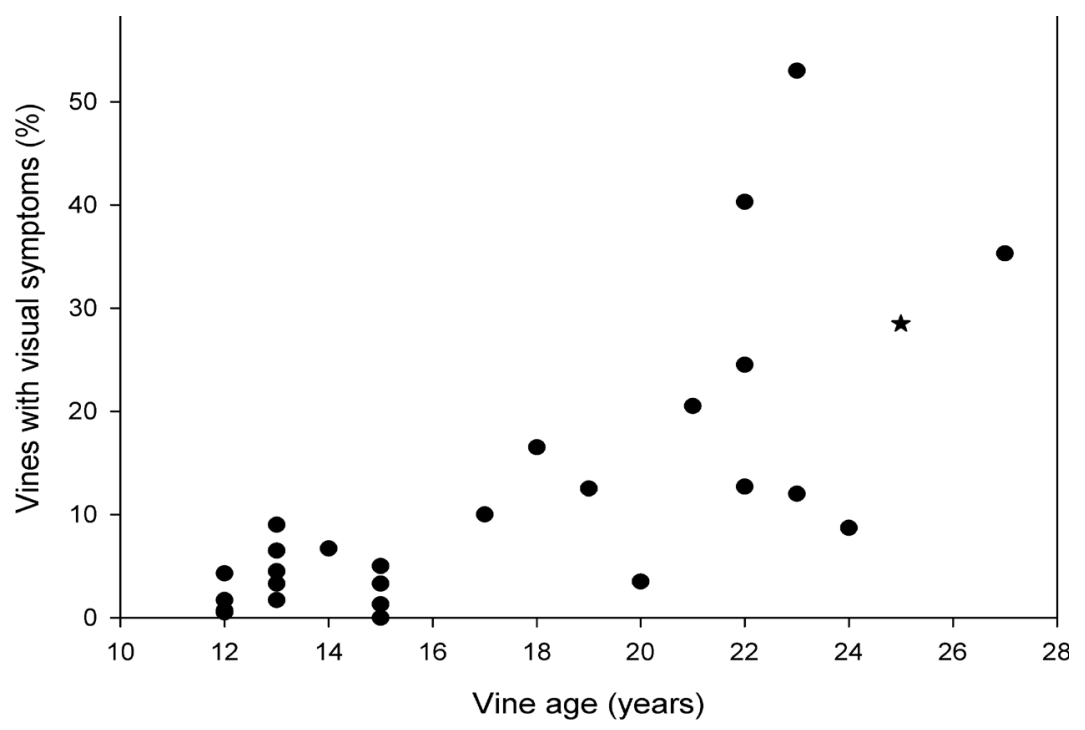

Figure 2 Percentage of Marlborough Sauvignon blanc grapevines on SO4 rootstock, visually assessed by the industry, with trunk disease symptoms in November-December 2013. Each point represents 200 vines sampled from within one of 27 blocks. Block 26 is indicated by a star and was the block used for the survey data presented in this paper. 
commercial wine company for 27 Marlborough Sauvignon blanc vineyards on $\mathrm{SO} 4$ rootstock in 2013 ranged between 0 and 53\% (Figure 2).

\section{DISCUSSION}

Currently the only method that wine companies have for a timely and economic assessment of trunk diseases is a visual assessment of symptoms, such as that seen in Figure 2, providing relative rates of symptom expression but not predicting vine deaths. Accurate prediction of vine deaths would enable growers to better manage the risk posed by trunk diseases. In this study, cumulative vine deaths of $16.7 \%$ occurred by the end of the observations and were not predicted by visual assessments. The wine industry data (Figure 2) demonstrated that there was a great deal of variation in visual trunk disease symptoms between blocks.

This study showed that within a block visual assessment between seasons was not consistent with decreases and well as increases over time. Therefore, management decisions for a vineyard block should not be based on a single time-point observation of visual symptoms. While the cause(s) of death for the vines in the study block

Table 1 Number (and percentage) of Marlborough Sauvignon blanc grapevines $(n=3784)$, which were either dead or had a gap, showed visual trunk disease symptoms or healthy on six survey dates between January 2006 and January 2016.

\begin{tabular}{cccc}
\hline & & Vine condition \\
\cline { 2 - 4 } Survey date & Dead/gap & Visual symptoms & Healthy \\
\hline Jan-06 & $34(0.9)$ & $223(5.9)$ & $3527(93.2)$ \\
Feb-08 & $112(3.0)$ & $732(19.3)$ & $2940(77.7)$ \\
Jan-09 & $199(5.3)$ & $664(17.5)$ & $2921(77.2)$ \\
Jan-13 & $402(10.6)$ & $169(4.5)$ & $3213(84.9)$ \\
Dec-14 & $598(15.8)$ & $524(13.8)$ & $2662(70.3)$ \\
Jan-16 & $639(16.9)$ & $621(16.4)$ & $2524(66.7)$ \\
\hline
\end{tabular}

Table 2 Trunk disease status on five previous survey dates of Marlborough Sauvignon blanc grapevines that were newly recorded as dead (or a gap) in January $2016(n=41)$. VS=Vine showing Visual symptoms.

\begin{tabular}{cccccccc}
\hline \multirow{2}{*}{$\begin{array}{l}\text { No. of } \\
\text { surveys } \\
\text { with } \\
\text { symptoms }\end{array}$} & Jan-06 & Feb-08 & Jan-09 & Jan-13 & Dec-14 & Jan-16 & $\begin{array}{c}\text { No. of vines } \\
\text { (\%) }\end{array}$ \\
\cline { 2 - 6 } & & & & & & & \\
\hline 4 & VS & VS & VS & Healthy & VS & Dead/gap & $1(2.4)$ \\
4 & Healthy & VS & VS & VS & VS & Dead/gap & $1(2.4)$ \\
3 & Healthy & VS & VS & Healthy & VS & Dead/gap & $8(19.5)$ \\
2 & VS & Healthy & Healthy & Healthy & VS & Dead/gap & $1(2.4)$ \\
2 & Healthy & VS & VS & Healthy & Healthy & Dead/gap & $1(2.4)$ \\
2 & Healthy & Healthy & Healthy & VS & VS & Dead/gap & $4(9.8)$ \\
1 & Healthy & Healthy & Healthy & VS & Healthy & Dead/gap & $1(2.4)$ \\
1 & Healthy & Healthy & Healthy & Healthy & VS & Dead/gap & $17(41.5)$ \\
0 & Healthy & Healthy & Healthy & Healthy & Healthy & Dead/gap & $7(17.1)$ \\
\hline
\end{tabular}


reported in this paper were not determined, it has been hypothesised that stress conditions in the grapevine, such as drought or low carbohydrate reserves, may increase the rate of vine mortality from trunk diseases (Mundy \& Manning 2011). Therefore, pre-season climatic conditions may influence both foliar symptoms and vine mortality in any given season. To help the industry to make decisions regarding replacement of individual vines or whole blocks, more studies are required to study the effects of climate on trunk diseases. More studies are also required to determine if the blocks with fewer symptoms result in fewer vine deaths over a short to medium term of 2-4 years. Past surveys of foliar symptoms of trunk disease have shown considerable variability from year to year (Sosnowski et al. 2007), and the observations in the current study confirm seasonal variation in visual symptoms, including foliar symptoms such as stunned shoots which are restricted to $E$. lata infections.

Within the survey area, individual vines that died were not sampled and the pathogen or pathogens present were not determined. It is possible that some of the vine deaths over time were due to other factors in the vineyard, such as mechanical damage. However, repeated collection of wood with $E$. lata fruiting bodies from the survey

Table 3 Number (and percentage) of Marlborough Sauvignon blanc grapevines either with visual symptoms of trunk disease $(n=223)$ or healthy $(n=3527)$ in January 2006, which were either dead (or a gap), showed visual trunk disease symptoms, or were healthy on six survey dates between January 2006 and January 2016.

\begin{tabular}{lllllccc}
\hline \multicolumn{3}{c}{ Survey } & \multicolumn{3}{c}{ Initially with foliar symptoms } & & \multicolumn{3}{c}{ Initially healthy } \\
\cline { 2 - 4 } \cline { 6 - 8 } date & Dead/gap & Symptoms & Healthy & & Dead/gap & Visual \\
symptoms & Healthy \\
\hline Jan-06 & $0(0)$ & $223(100)$ & $0(0)$ & & $0(0)$ & $0(0)$ & $3527(100)$ \\
Feb-08 & $32(14.3)$ & $147(65.9)$ & $44(19.7)$ & & $46(1.3)$ & $585(16.6)$ & $2896(82.1)$ \\
Jan-09 & $54(24.2)$ & $128(57.4)$ & $41(18.4)$ & & $111(3.1)$ & $536(15.2)$ & $2880(81.7)$ \\
Jan-13 & $76(34.1)$ & $18(8.1)$ & $129(57.8)$ & & $292(8.3)$ & $151(4.3)$ & $3084(87.4)$ \\
Dec-14 & $96(43.0)$ & $30(13.5)$ & $97(43.5)$ & & $468(13.3)$ & $494(14.0)$ & $2565(72.7)$ \\
Jan-16 & $98(43.9)$ & $37(16.6)$ & $88(39.5)$ & & $507(14.4)$ & $584(16.6)$ & $2436(69.1)$ \\
\hline
\end{tabular}

Table 4 Isolations by fungal genus associated with live Marlborough Sauvignon blanc grapevines with and without visually assessed trunk disease symptoms in 2007.

\begin{tabular}{lcc}
\hline & Visual symptoms $(\mathrm{n}=11)$ & No Symptoms $(\mathrm{n}=11)$ \\
\cline { 2 - 3 } Botryosphaeria & 3 & 4 \\
Cylindrocarpon & 0 & 1 \\
Eutypa & 5 & 2 \\
Phomopsis & 2 & 3 \\
Basidiomycete & 2 & 1 \\
Fusarium & 0 & 4 \\
Gliocladium & 1 & 2 \\
Phialophora & 1 & 1 \\
\hline Number of vines dead & 5 & 0 \\
by December 2015 & \multicolumn{2}{c}{ Eleven vines had more than one genus isolated from a single vine, and three vines had no successful } \\
isolations. &
\end{tabular}


block, and visible cankers on many of the vines, as well as isolation of E. lata and Botryosphaeria spp., have resulted in the wine company managing this block as a trunk-diseased area. Currently, the only management options available when a vine dies are replanting or leaving the vine space empty. Cost:benefit decisions on replanting have been calculated using short-term data for vine deaths (Mundy et al. 2014), but these calculations need to be updated with longer-term information on mortality from blocks of disease-tested vines and from more than one site. The slope of the cumulative vine loss for a given vineyard block maybe different from the observed rate at the study site (Figure 1). Different rates of vine deaths will affect the cost:benefit of replacing vines.

This study did not show a direct relationship between the initial visual assessment of vines at a single time point and vine death over time. It showed vines that died without any prior symptoms (Table 2), and also vines showing symptoms at multiple sampling times that did not die during the study (data not presented). To make better predictions of vine deaths due to trunk disease, direct non-destructive sampling of vines and then observation over time will be required, linked with detailed records of weather data and vineyard management practices. Information of this type would be required to test the hypothesis that conditions for symptom expression are different from those for infection and colonisation (Mundy \& Manning 2011). However in the meantime, repeated visual assessments of vineyards over time may give an indication of which blocks are most likely to require replanting, based on relative symptom expression.

Direct sampling of vines and observation over time would also allow an investigation of the whole microbial communities within the wood, to determine if correlations exist between in-vine microbes and symptom expression. Investigations of this type have recently been reported from France, with numerous mycoparasites and saprobes detected, as well as plant pathogens (Bruez et al. 2014). Future research should also determine if there is a correlation between trunk disease risk and seasonality, and the best time to sample for these pathogens.

\section{ACKNOWLEDGEMENTS}

Many thanks to Pernod Ricard New Zealand for allowing access to their vineyard, and for providing data on relative occurrence of visual symptoms in other blocks. Thank you to Victoria Raw, Pratap Vanga and Rachel Bishell of Plant \& Food Research for help with the data collection. This work is part of the New Zealand Grape and Wine Research programme, a joint investment by Plant \& Food Research and NZ Winegrowers. We would also like to thank Robert Beresford and Karmun Chooi, Plant \& Food Research, for reviewing this manuscript.

\section{REFERENCES}

Anonymous 2000. The Bank of New Zealand Wine and grape industry statistical annual. Auckland, N.Z., Winegrowers of New Zealand. Pp. 44.

Baumgartner K, Travadon R, Cooper M, Hillis V, Kaplan J, Lubell M 2014. An Economic Case for Early Adoption of Practices to Prevent and Manage Grapevine Trunk Diseases in the Northern California Region: Preliminary Results: Research brief. Center for Environmental Policy and Behavior.

Bruez E, Baumgartner K, Bastien S, Travadon R, Guerin-Dubrana L, Rey P 2014. Pathogenic fungi and mycoparasites colonizing the functional wood of old vines with no Eutypa dieback or Esca foliar symptoms. 9th International Workshop on Grapevine Trunk Diseases, Adelaide. Pp. 28

Gubler WD, Rolshausen P, Trouillase F, Urbez JR, Voegel T, Leavitt GM, Weber EA 2005. Research update: Grapevine trunk diseases in California. Practical winery \& vineyard Magazine Jan/Feb. p. 6-25.

Mundy DC, Cocchi C 2007. An evaluation of the impact of grapevine trunk disease on fruit quality and vine performance in the Marlborough region, New Zealand. The 13th Australian Wine Industry Technical Conference, Adelaide Convention Centre, 
Adelaide, South Australia. Pp. 79.

Mundy DC, Manning MA 2010. Ecology and management of grapevine trunk diseases in New Zealand: a review. New Zealand Plant Protection 63: 160-166.

Mundy DC, Manning MA 2011. Physiological response of grapevines to vascular pathogens: a review. New Zealand Plant Protection 64: 7-16.

Mundy DC, Casonato SG, Manning MA 2009. Incidence of fungi isolated from grape trunks in New Zealand vineyards. The Australasian Plant Pathology Society 2009, Newcastle City, NSW Australia. Pp. 86.

Mundy DC, Raw V, McLachlan ARG 2014. Calculating the economic cost of trunk disease spread. International workshop for Grapevine Trunk Diseases, Adelaide.
New Zealand Winegrowers 2014. Annual report. Auckland, N.Z. Pp. 32.

Sosnowski MR, Shtienberg D, Creaser ML, Wicks TJ, Lardner R, Scott ES 2007. The Influence of Climate on Foliar Symptoms of Eutypa Dieback in Grapevines. Phytopathology 97(10): 1284-1289.

Sosnowski M, Ayres M, Wicks T 2012. Kangaroo Island grapevine trunk disease survey. South Australian Research and Development Institute.

Wicks T, Davies K 1999. Effect of Eutypa on grapevine Yield. The Australian \& New Zealand Grapegrower \& Winemaker (Annual Technical Issue): 15-16. 